on the study of other contagia, which, he thought, ought to be investigated in the same manner, even though the contagia should prove to be very different in their nature. The facts which he had detailed showed that this disease followed the same laws of non-recurrence, or of recurrence in a modified form, which held good of most known specific febrile diseases; that, in like manner, variable susceptibility or unsusceptibility had their due effect. The contagium had selective properties for sites of attack in different animals, and of vehicles of transport, and in many ways presented characters not unlike those of parasites. Further research amongst known contagia would, no doubt, lead to the discovery of properties which would be of the greatest value in their bearing on the prevention and cure of other diseases of which the contagia had not hitherto been discovered.

\section{LECTURE V}

Was occupied by demonstrations of, and remarks upon, the specimens which Dr. Greenfield promised to show, to substantiate the hypotheses and observations he had promulgated in his four previous lectures.

He showed a series of micro-photographs-which had kindly been prepared for him by Dr. Maddox--illustrating the changes which the Bacillus anthracis undergoes in its growth, and the various stages it assumes during artificial cultivation. He also exhibited some of the blood and other fluids from cases of human anthrax (woolsorters' disease), as well as some from various other animals. These were most effectively shown with the lime-light by Dr. WV. H. Stone.

In another room, a series of microscopical specimens were arranged, showing some very clear and beautiful specimens of anthrax bacillus under cultivation, in the various tissues of the human and lower animal bodies; also some specimens of other organisms which might be mistaken for those of anthrax.

\section{CASE OF PROGRESSIVE MUSCULAR ATROPHY, WITH BULBAR PARALYSIS.*}

By ARTHUR W. FOX, M.B.,

Physician to the Eastern Dispensary and Bellot's Minera! Water Hospital, Bath.

ON December 4th, 1879 (by the advice of my friend, Mr. Michael, who most kindly transferred the patient to my sole care), I was consulted by H. E., who complained of loss of power in his hands and arms. The note of his condition was as follows. He was forty-five years of age, and was a master blacksmith. When a boy he broke his right arm, and when fourteen or fifteen years old injured the second finger of his right hand, which resulted in its loss through necrosis at the second joint. With the exception of "five or six touches of gout" he had always enjoyed excellent health. He had never been laid up a day through illness. (I subsequently learned from his wife that three years ago he fell back on the bed one morning in "some sort of fit", in which he was unconscious, and foamed at the mouth; "this occurred when he was passing urine".) He was always a steady man, "never a drinker". He never had venereal disease of any kind. He had been married for years. There was no hereditary tendency to nervous disease of any kind. He had not been exposed to any special mental worry.

There was nothing special in his general appearance; his hair was turning grey. He had been, from all accounts, a remarkably muscular man, with splendid arms. Until recently he could snap any ordinary piece of string by tying it tightly round his arm and then flexing his fore-arm, and causing his steel-like biceps to bulge. The weakness in his hands and arms began about two months ago, and the first symptom he noticed was difficulty in buttoning his clothes. At the beginning of these symptoms he perspired profusely; this was not the case at present. There was wasting of the deltoids, with fibrillary tremor. The grasp of the hands was feeble, but especially so on the right side. He was unable to oppose the right thumb to the little finger, or to flex either thumb into the palm ; there was loss of power in the interossei on the right side, and there was a certain appreciable amount of wasting of the muscle of the ball of the right thumb. He could raise his arms, but with some difficulty, over his head ; could join his hands behind his back, and could extend, flex, and pronate the fore arms. He could frown, show his upper teeth, laugh, whistle, and cough. There was free movement of his jaws. His speech was slightly husky. His wife stated that it was not his natural voice, and that she had noticed this change for about a month. Ile was able to articulate clearly and dis- tinctly. He had noticed lately that when he ate there was a greater tendency for food to collect between his cheeks and gums. He was perfectly able to swallow. He stated that he was unable to move his tongue round between his gums and cheeks as well as formerly. $\mathrm{He}$ could protrude his tongue straight out, and move it to either side, and the tip up to the hard palate, but when it was protruded he was unable to turn the tip up towards the nose ; there was no noticeable tremor or wasting of the organ. His pupils were equally contracted to a pin's point, and were totally unaffected by light. His vision appeared to be good, but his discs were not examined, as the extreme myosis would have necessitated the use of atropin, which would have inconvenienced him in his work. There was no affection of smell, taste, or hearing. There was no affection whatever of sensibility; the reflexes were normal. There was no ataxia. He could walk and stand with his eyes closed. During the last two months he had been troubled with constant yawnings and grinding of his teeth. During this month he had found a loss of sexual power. Pulse 88, small, feeble, and regular. Temperature 97.6. The respiratory and circulatory systems were normal. The hepatic and splenic dulness was normal. The appetite was very good. The bowels were lately costive. There was no affection of micturition. The urine was of specific gravity 1025, containing traces of sugar. He had no pain anywhere. His memory was good. $\mathrm{He}$ was neither emotional nor irritable. He slept well. I ordered him to take twice a day a quarter of a grain of nitrate of silver in pill, and to use galvanism. It is needless to say that the diagnosis was progressive muscular paralysis, with commencing bulbar symptoms.

Between this date and March 7 th, I880, I occasionally saw him. There was rapid wasting of the muscles of the shoulder and arm on both sides, including the deltoids, biceps, and triceps. His scapulæ assumed a somewhat winged appearance, from the serrati being involved. There was also rapid wasting of the muscles of his fore-arm and hands, especially of the muscles of the kalls of both thumbs, and the interossei. For the last two months he had become so powerless from the loss of muscle in the hands and arms, as to be utterly unable to do anything for himself. His wife stated that every day the wasting appeared to get worse. He was troubled with incessant fibrillary quivering all over his body. Lightly tapping his muscles excited there contractions to a marked degree. There was no loss of muscle in his legs. His face assumed a haggard and aged appearance, with deepening of the furrow between the ala of the nose and the angle of the mouth. He was able throughout to keep his lips fairly closed, but not sufficiently tight to prevent the incessant dribbling of saliva, which greatly distressed him. This flow of saliva, making every allowance for his increasing difficulty in swallowing, was evidently increased in quantity, and was alsooccasionally tinged with blood. At Christmas time he was able tomasticate a beef-steak, but for the last fortnight, from about the third week in February, his meat required to be minced very fine ; evidently there was impairment of the pterygoid muscles. During February, deglutition became so affected as to render it impossible for him to drink thin liquids. His speech, which I noticed to be husky when I first saw him, rapidly became more and more difficult to understand, and by the middle of February it was to me perfectly unintelligible; it had a marked nasal tone, evidently from the palate being affected. $\mathrm{He}$ was still able with difficulty to protrude his tongue a little beyond the lip, but was apparently unable to move it in any other direction. There was no visible wasting of the organ, nor wrinkling of the upper surface. His sexual desire had completely disappeared. $\mathrm{He}$ suffered from profusc perspirations. His wife noticed that latterly his perspiration was "peculiarly unpleasant, as if he were dead". The extreme myosis was present from first to last. On March Ioth his wife noticed that he was more restless than usual; he smoked a pipe in the evening, which shows the amount of power he still retained in his orbicularis oris.

On March IIth he went out in a chair in the morning, but upon his return became so much worse that they sent for me. As I was out of town my friend, Mr. Green, kindly saw him, and took the following notes of his condition.

"March IIth.-At noon to-day I was called to see H. E., a patient of Dr. Fox, who was out of town. He appeared to be dying. He was sitting in a chair, his face was of a dusky pallor, his lips of a purple colour. There was very little power to raise the drooping eyelids. Both his arms were completely paralysed, and when about to ascertain if a similar condition existed in his legs, he immediately stood upright without support, and even walked across the room with slight support, in order to show me that he had no loss of power in his lower extremeties. Sensation was perfect in both arms and legs, but he complained of great pain in both legs. There was some twitching of the adductor pollicis, and also of the facial muscles, and extreme myosis of both pupils, which were evenly contracted to a pin's point. The 
ribs were perfectly immobile, and the respirations were abdominal, 30 per minute, very shallow, and effected without any spasmodic effort. His bronchial tubes were filled with mucus, and this appeared to be killing him. Not once during my visit did he cough or make any effort to expel the mucus. He once assumed the horizontal position, which caused great distress, and was quickly abandoned. His pulse was 80, with good power. The feet were quite warm. The intellect was un affected. A dribuling of saliva, which had been present during his illness, had ceased during the last twenty-four hours. I could not help being struck at seeing him dying, and yet being able to stand without support, and even to walk with only slight assistance. He died six hours alter my visit, asphyxiated."

Permission was given to examine the brain and spinal cord, which were removed, in my presence, by my friend Mr. Scott, on March 12 th, twenty-two hours after death.

The brain, its membranes, and vessels, were perfectly normal to the naked eye; and the same with regard to the cranial nerves; there was certainly no appreciable wasting. The pons, medulla, part of the cerebellum, the whole of the cord and its membranes, were first placed

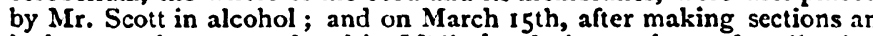
inch apart, they were placed in Muiller's solution; when, after allowing them to harden for some days, I availed myself of my friend Dr. Shingleton Smith's kindness and well-known skill, and submitted them to him for an exhaustive examination. The following is the report with which he has inost kindly furnished me.

Kicport on Spinal Cord and Medulla Oblongata.-The specimens had been divided transversely at frequent intervals, and prescrved in Miiller's fluid. On naked eye examination, nothing very decided was visible externally. The whole area of the cord did not appear to be diminished; the natural shape of the cord was retained; there was no grey degeneration visible on the posterior aspect. The membranes were not unduly adherent, and there was no visible atrophy of the roots of the nerves. On examining transverse sections of the cord in the different regions, the following changes could be made out.

In the cervical, the substance was decidedly softer than in the normal state, after similar treatment with Miuller's fluid, the grey matter being softer than the white; the horns were quite distinct in outline, but the right anterior was smaller than the left; the right half of the grey matter was also much softer than the left, and was casily disintegrated. At the lower cervical region, in the cervico-brachial bulb, the left half appeared to be softer than the right, and the outline of the anterior horns was indistinct on both sides. A short distance below, the cord was slightly flattened in shape on its anterior aspect. The grey matter was scarcely visible, and the whole substance tore readily un endeavouring to make sections.

In the upper dorsal portion, softening was present, more particularly the anterior portion; the anterior horns were indistinct in outline, and were pale in colour, but not disintegrated. The posterior columns, and the lateral columns, were of a greyish colour, but equally so on the iwo sides.

In the lumbar region, the cord was of normal consistence and appearance. The outline of the grey matter was well defined, and no difference could be perceived betwcen the two sides.

The medulla oblongata and pons Varolii did not present any abnormal appearances.

On microscopic examination, it was found that the grey matter was the part chiefly involved, and more particularly so in the lower cervical and upper dorsal regions; where the disease was most advanced, the grey matter had bccome much fissured and lacerated in the process of tiaking sections and mounting; here the vessels were found to be very 1:umerous, the whole mass of grey substance became deeply stained with aniline; but no normal nerve-elements could be distinguished. The mass presented a granular appearance, with numerous darkened spots scattered throughout, some of which were blood-vessels in seciion, others were the remains of nerve-cells, and some were inflammatory products. The central canal was much enlarged, and its cavity "ccupied by a mass of rounded granular epithelial cells. The nervecells of the anterior cornua had lost their proccsses and nuclei, and tecome much atrophied and granular. The trabecula of neuroglia were too numerous, running through the white matter; but the axiscylinders of the fibres in the white matter were quite distinct, close up to the edge of the grey substance. No inflammatory products were visible in the white substance, and no amyloid bodies could be made cut.

In the upper dorsal region, the disintegrating process had given rise to the formation of spaces in the grey matter, lined by a false membrane, and occupied by inflammatory dibris; one such space was in immediate proximity to the central canal on its right side, and another, less de!ined, was near the tip of the right anterior horn. The cells of Clarke's column were less rumerous and smaller on the right side than on the lefi. $\Lambda$ few shrivelled cells could be made out in both anterior cornua. The central commissure was thickened anitcro-posteriorly; the central canal was obliterated ly epithelial proliferation; the vessels around it were large and numcrous. The anterior, lateral, and posterior columns, contained a small mass of blood-vessels, and of trabecula of neuroglia, but the nerve-fibres were healthy.

In the lumbar region, the central canal was expanded laterally, its cavity obliterated, and its prisition occupicd by a mass of granu!ar cells and granular ditris. The grey matter became less deeply stained than that in the dorsal region; there were no patches of disintegration, and the blood.vessels were less numerous. In the anterior horns, groups of well-formed nerve-cells, with processes, were visible on each :ie; but other cells, smaller in size, without processes, not stained, an! containing yellow pigment, were also resent; and other bodies, locking like amyloid corpuscles were scattered sparsely throughout the grey n:atter, and a few also in the anterior white columrs. In the nosterior collumns the trabeculre were slightly thickenect, but the axis-cylinders were well stained, and of uniform sizc.

In the medulla, below the ciccissation of the pyramids, the grey matter was found to be riddled with small cavities, snd a circular patch, surrounding the central canal, becime decply stainice! with aniline. The canal was much elongated antero-posteriorly, and its cavity was olliterated by epithelium. The anteriur yramids, and the olivary bod:es, presented no abnormalities. At ihe higher 1.ortion of the msluila, the sections presented no abnormal stainirg; thire was no cxcess of bloodvessels, and the nerve structures were perfect!y healthy.

To sum up, the appeurances were those of myelitis affecting the grey matter, more particularly that of the anteriur cornua, most markcid at the upper dorsal region, but extending uwards around the central canal into the medulla, and terminating below the calanius scriptorius.

REMARKS. - It would take up too much timc this evening, and probably only weary you, if I were to attempt to discuss all the various theories in conncetion with this interesting disease. Whether it is from the first a central affection of the spinal cord, in which the large multipolar cells in the anterior horns are involved, or whether it is primarily a peripheral condition, beginning in the muscles as a chronic myositis, affecting secondarily the intramuscularrerves, and, through an ascending neuritis, giving rise to myelitic proccsses in the cord itself; or, thirdly, whether it is an affection of the sympathetic, a fatty degeneration, as Jaccoud, Remak, Swarzanski, ard others maintain.

Excepting Friedreich, and some others of the German.school, who persistently cling to the mynpathic theory, and who consider that only by this theory can the great varieties of the morbid conditions found in the nervous system be cxplained ; the majority of pathologis:s in this country and abread, including Lockhart Clarke and Charcot, are agreed, that in most instances the cord itself is primarily at filtilt, and the disease essentially is a degenerative atrophy of the large cells in the anterior horns; and that, when there is a development of buit:ar $5 y \mathrm{~m}$ ptoms, there is an extension of this primary process to tha group of nuclei in the medulla oblongata.

Still, as Wilks remarks (Disases of the Nerrous Systcm, prige 25I), cases occur in which the disease appears to have had its staring point at the periphery; and he refers to the case of a man, whosc ain after an injury became wasted, and whose other arm and leg after a time became involved; and at the present time, I have under ny care a young girl who presents a typical clinical picture of progressive miuscular atrophy, and whose sjmpioms datc from her having beer vid!ently swung round by the hands by anviher girl, who suddenly let go of her. the result being; that she fell to the ground, and was stunned. And Icnding some apparent support to this view, is the fact that riechanics are frequently the victims of this disense; Irammond (Discinis if the Nervous Sy'stim, page C(9), mentions the case of a ballet-iumer in whom the sural muscles were affected, and IIamilton (Nirious Dis. eases, page 259), has scen the same limited atrophy in a cigar-maker and a compositor, who used ccriain groups of muscles almost censilantly. In H. E.'s case, it is important to bear in mind his occupation : that he was a blacksmith, who did a large amount of manual work himseif, and that his discase at the commenecnent was most marked in his right hand and arm; this m: hht lead one naturally to suppose that overwork of a muscle may cause its subsequent atrophy, but it may equally be said that the same overwork and fatigue may give rise to $i$ degenerative atrophy of the delicate nerve.centre in the cord, which r tiles over the nutrition of the muiscle. And opposed, I consider, to the thecry that the lesions in this paitent's cerd are the final results of a myositis through overwork, which affected seconda:ily the nerve-1..ths, and through a continuation of the inflammatory process, as an accending neuritis, caused the changes in the cord you wil! see under the micro- 
scope, is the fact that neither to the naked eye nor upon microscopic examination did Dr. Smith find any changes worthy of notice in the anterior roots; and this appears to me to be an argument of some weight against the supposition that the disease in this man began at the periphers:* $\Lambda \mathrm{n}$ additional evillence in favour of its being primarily a central affection was the carly development of symptoms pointing to an implication of the nuclei of the hypoglossal, the vagus, and the spinal accessory nerves; and after a while the fifth, and to some extent the seventh. As related in my report, when he first came to see me, I noticed that his roice was husky, and the movement of the tip of his tongue upwards was not as free as it ought to have been.

Among the clinical features presented by this case may be noted, firstly, the duration of the disease, its comparative rapidity, which can easily be accounted for by the extension of this polio-myelitis of the cervico-brachial bulb upwards to the medulla, and the involvement therefore of the respiratory centres; secondly, the extreme degree of myosis, which Fulenberg states (Zicmessin's Cyclopactia, vol. xiv, page 127) to be a very rare complication of progressive muscular atrophy : as Duchenne, among several hundred cases, never once met with this phenomenon. With regard to the perspiration from which H. E. suffered throughout his disense, its appearance in the initial stage, before there was any high degree of muscular atrophy, tells forcibly against Friedreich's explanation that it was the result of a collateral fluxion to the cutaneous vessels, caused by obliteration of a large number of the finer muscular vessels in the rapid atrophy of the muscles. The probability is, that it was due to the amount of disease in the cilio-spinal region. Whether there was any sisc of temperature during these sweats $I$ am unable to say.

An interesting fact in connection with this case, was the absence of dribbling of saliva for the last twenty-four hours of his life. Whether or no there is an actual increase of the amount of saliva secreted in thesc cases of lulbar disease, authorities differ. Both Erb and Kussmaul consider that there is an increased secretion; and Schultz estimated in one case a six or eight-fold secretion. Granting, however, the truth of Gructzner's experiments, which go to prove the existence of a cenfre of salivation in the medulla, irritation of whicil causes active salivation, it is difficult to understand, as Erb remarks, how, in a case of bulbar disease, there can be irritation of this centre, when all the other bulbar functions are paralysed.

With regard to the treatment of this case, I gave nitrate of silver, because Kussmaul recommends it in preference to any other medicine; but I am afraid that, in our present state of ignorance, but little can be said in favour of any drug doing any permanent amount of good. In a case, which wis reported in the April number of the London Micdical Record for this year, of progressive muscular atrophy, apparently of syphilitic origin, a remarkable improvement, amounting almost to com. plete recovery, followed the administration of iodide of potassium ; but no mention is nade as to whether or not electricity was used, and this is an important omission, for probably more benefit may be expected from the stimulating effect of electricity upon the trophic cells than any other remedy. Erb recommends the galvanic current; and so does De Wattcrille, with faradisation for the muscles.

Concerning the pathological appearances found by Dr. Smith in the spinal cord, it is unnecessary to detain you any longer, as you have the opportunity of inspecting for yourselves the beautiful sections he has been so kizd as to bring with him this evening.

Since writing the forcgoing, I have found that Feinberg's experiments on rabbit tend to prove that myelitis may resuit from peripheral irritation without inflamma tion of the intervening structures; and, therefore, instcad of this change in the grey matter of the cord bcing due to a continuation of the inflammatory process as an ascciding neuritis, it is caused by some reflex influence through the vaso-inotor s)'steu.

WHITECHAPEL. - In the third quarter of 1880 there were 590 births and 43I leaths in Whitechapel, to which must be added an unknown number of deaths of residents in public institutions outside the district. Ninety-eight deaths occurred from zymotic diseases, the larger portion of these (70) being due to diarrhœa. The deaths amongst children under one year of age were 138 , or 24.8 of the total mortality, and the deaths amongst children under five years 247 , or 42.4 per cent. of the total desths. In spcaking of the prevalence of enteric fever in London, Mr. Liddle has some very interesting observations on the influence of filth in the causation and spread of the disease, in which he urges the great importance of vigilance on the part of the sanitary officers.

\section{ON WOUND-TREATMENT: PRINCIPAL AND ACCESSORY.*}

Br SAMPSON GAMGEE, F.R.S.Ed., Surgeon to the Queen's Hospital, Birmingham.

Ar the opening of this session, I addressed to our colleagues in the Birmingham Branch some discussions on the relative merits of different methods of wound-treatment, which were favoured with the valued privilege of prompt publicity through the columns of our Journal (British Menical. Journal, October 30th, 1880).

As the date is so recent, and the subject so interesting, I trust it is not presuming too much to take for granted that most of those whom I have the pleasure of addressing are acquainted with the substarce of the paper referred to. It has evoked numerous expressions of general agree. ment, and, to my knowledge, only one of dissent. But that one is of peculiar significance, and has placed me under the deepest obligation; for it emanated from a critic distinguished by acumen and experience. He "thinks it quite as likely that I should prove right in the matter as anyone clse, but $I$ have not proved my case in the least. I have not even touched the fringe of the matter. No one doubts that excellent results can be secured by rest and dry dressing ; but the real test must be a set of psoas abscesses; open them with all Listerian antiseptic pre. cautions, and without them, and sce what becomes of dry dressings and of the poor patients." As my writer went on to disapprove the tone in which I had referred to Mr. Lister, I take this opportunity, the earliest public one I have had since the publication of my paper, to express sincere regret if in form or substance $m y$ criticism unintentionally exceeded the bound of professional courtesy and of true friend. ship.

The former communication disclaimed all pretence to completencss; and was a vowedly sketchy and suggestive for purposes of debate. It is hoped that it may be usefully supplemented by the observations which I am about to address you; but it will be impossible, even now, to do much more than touch the fringe of a subject, the boundaries of which are practically conterminous with the surgical domain.

I may at once disclaim intention of attempting to illustrate the essentials of wound-treatment from the consideration of psoas abscesses which involve special pathological conditions.

An incision through the scalp to turn out a cystic tumour, and an opening of similar dimensions in Scarpa's triangle to evacuate a collection of pus, which has travelled down from a centre of decaying bone in the spine, differ so widely as to preclude comparison, without violence to the first principles of scientific reasoning.

I Iaving published the circumstances of a case in which I opened a fotid spinal abscess under the carbolic spray, with the most signal benefit, I venture to ask your attention to the remarks which I appended to it.

"The result in the brilliant case just recorded, is unquestionably duc to the measures adopted, - carbolic spray dressing and immobilisa. tion. I shall not here stop to inquire whether the spray acted by intercepting and destroying the atmospheric germs, or by a chemical or pickling action. What I contend is, that it is an error to deducc from any number of such cases of fœtid spinal abscess, rules applicablc to the treatment of wounds in healthy structures. A friori predication from physiological to pathological conditions has been one of the most fertile sources of error in the whole range of medical science. It can. not be conceded that the results of experiment in pathological conditions and dead organic matter, should a fortiore, be held to apply to healthy statcs and living structures". (Lancet, 1879, vol. ii, p. 457.)

It is in the simplest injuries in healthy tissues, and in parts of the body accessible to accurate co-aptation, drainage, and pressure, that we can best study the phenomena of traumatism and repair, and the action of therapeutic resources, so as to form a sound judgment on wound-treatment, principal and accessory.

Let us assume a series of cases of injury of the forc-arm, such as you are all certain to have seen repeatedly in practice. Firstly, a casc of fracture of radius and ulna, about the middle, without complications, comes under treatment directly after the accident. Immediate reduction and careful adjustment is followed by consolidation, which is painless and rapid in direct proportion to the perfection of the apparatis. To secure absolute rest, the joints above and below the seat of injury must be fixed, and muscular action controlled effectually. The less the part is disturbed, the better; union takes place without swelling of the soft parts, and without thickening of the bone. As Percival Pout long since pointed out, simple fractures unite by direct intervention of 